\title{
A Metallomic Approach to Assess the Associations between Plasma Metal Levels with Amnestic Mild Cognitive Impairment and Alzheimer's Disease: A Cross-sectional and Longitudinal Study
}

\section{Yu-Kai Lin}

Tri-Service General Hospital Department of Neurology https://orcid.org/0000-0002-8995-8375

Chih-Sung Liang

Tri-Service General Hospital Beitou Branch

Chia-Kuang Tsai

Tri-Service General Hospital Department of Neurology

Chia-Lin Tsai

Tri-Service General Hospital

Jiunn-Tay Lee

Tri-Service General Hospital Department of Neurology

\section{Yueh-Feng Sung}

Tri-Service General Hospital Department of Neurology

\section{Chung-Hsing Chou}

Tri-Service General Hospital Department of Neurology

\section{Hung-Sheng Shang}

Tri-Service General Hospital

\section{Bing-Heng Yang}

Tri-Service General Hospital

\section{Guan-Yu Lin}

Tri-Service General Hospital Songshan Branch

\section{Ming-Wei Su}

Institute of Biomedical Sciences Academia Sinica

Fu-Chi Yang ( $\sim$ fuji-yang@yahoo.com.tw)

Tri-Service General Hospital https://orcid.org/0000-0001-6831-3634

\section{Research}

Keywords: Alzheimer's disease, mild cognitive impairment, trace metals, biomarkers, in vivo assessment

Posted Date: April 9th, 2021 
DOI: https://doi.org/10.21203/rs.3.rs-396037/v1

License: (c) (i) This work is licensed under a Creative Commons Attribution 4.0 International License. Read Full License 


\section{Abstract \\ BACKGROUND}

Alzheimer's disease (AD) involves the abnormal activity of transition metals and metal ion dyshomeostasis. The present study aimed to assess the potential of 36 trace elements in predicting cognitive decline in patients with amnestic mild cognitive impairment (aMCl) or AD.

\section{METHODS}

All participants (controls, aMCl, and $\mathrm{AD}$ ) underwent baseline cognitive tests, which included the MiniMental State Examination (MMSE) and plasma biomarker examinations. We conducted a trend analysis for the cognitive tests and plasma trace elements and examined the correlations between the latter and annual MMSE changes during follow-up.

\section{RESULTS}

An increase in the disease severity was linked to lowered boron (B), bismuth (Bi), thorium (Th), and uranium $(U)$ plasma concentrations (adjusted $\mathrm{P}<0.05)$. "B", mercury $(\mathrm{Hg})$ and "Th" levels could detect different cognitive stages. " $\mathrm{B}$ " displayed high area under the receiver operating characteristic curves (AUCs) for aMCl and $A D$ versus controls (97.6\%, cut-off value: $\leq 73.1 \mathrm{ug} / \mathrm{l}$ and $100 \%$, cut-off value: $\leq 47.1$ ug/l, respectively). " $\mathrm{Hg}$ " displayed the highest AUC result to differentiate AD from aMCl (79.9\%, cut-off value: $\leq 1.02 \mathrm{ug} / \mathrm{l})$. Higher baseline levels of calcium $(r=0.50, p=0.026)$ were associated with less annual cognitive decline. While higher baseline levels of " $B$ " ( $r=-0.70, p=0.001)$, zirconium $(r=-0.58, p=$ $0.007)$, "Th" ( $r=-0.52, p=0.020)$ were associated with rapid annual cognitive decline in the aMCl group, those of manganese $(r=-0.91, p=0.035)$ were associated with rapid annual cognitive decline in the $A D$ group.

\section{CONCLUSION}

Plasma metal level biomarkers can be used as an in vivo tool to study and identify patients with aMCl and $A D$.

\section{Background}

Alzheimer's disease (AD) is a chronic progressive neurodegenerative disease that is usually mild at first and gradually worsens over time. It is the most common cause of dementia [1]. AD typically presents with amnestic syndrome, characterized by poor learning ability with memory loss or atypical variants, manifested as an early impairment of language function (aphasic variant), visuospatial function 
(posterior cortical atrophy), executive function (frontal/behavioral-comportamental variant), and motor function (corticobasal syndrome) [2].

Mild cognitive impairment $(\mathrm{MCl})$ is an intermediate state between the cognitive changes observed in normal cognition and symptomatic pre-dementia [3]. Patients with $\mathrm{MCl}$ demonstrate unexpected cognitive impairments, based on their age and education level. However, in $\mathrm{MCl}$, the disease severity does not meet the criteria for dementia [4]. A meta-analysis of 34 studies reported on a 10-20\% prevalence of $\mathrm{MCl}$ in adults aged $\geq 65$ years [5]. Amnestic $\mathrm{MCl}(\mathrm{aMCl})$ is frequently observed as a prodromal stage of $A D$, with an annual conversion rate of up to $25 \%[4,6]$. The aforementioned statistics highlight the importance of early diagnosis and intervention for patients with aMCl [7].

The National Institute on Aging and Alzheimer's Association (NIA-AA) as well as the International Working Group have focused on a biomarker-based definition of $A D$, emphasizing on the importance of $\beta$-amyloid $(A B)$ deposition, pathological tau, and neurodegeneration in the AD continuum $[8,9]$. The accepted biomarkers are amyloid positron emission tomography (PET) ligand binding, atrophy on structural magnetic resonance imaging (MRI), hypometabolism in fluoro-deoxyglucose (FDG)-PET, and several cerebrospinal fluid (CSF) proteins, such as low levels of $A \beta 42$ (or a $A \beta_{42} / A \beta_{40}$ ratio), elevated total tau (Ttau), and elevated phosphorylated tau (P-tau). Nevertheless, CSF collection is an invasive procedure and should only be performed by a technical physician, which limits access. Similarly, the high cost and laborintensiveness of neuroimaging also limits the wide-spread application in primary care or clinical officebased settings. For this reason, there is limited evidence for the inclusion of CSF biomarkers or PET markers in $\mathrm{MCl}$ and $\mathrm{AD}$ diagnosis during routine clinical practice [10]. Therefore, less invasive and economical blood-based biomarker testing, as well as genetic, clinical and demographic information will likely play an important role in population screening in the future.

Abnormal transition metal activity plays a critical role in the pathogenesis of AD [11-13].

Dyshomeostasis and the concentration of metal ions in neurofibrillary tangles, senile plaques, and the CSF support this concept [14]. Specifically, dyshomeostasis and the generation of toxic A $\beta$ oligomers are likely responsible for the $A D$-associated synaptic dysfunction. Therefore, the inhibition or prevention of amyloid plaque aggregation, the pathological hallmark of $A D$, may be treated through the targeting of metal ions, metal complexes, or metal-protein compounds, such as metal chelators is a potential therapeutic implication. This highlights the significant role of metals in the etiology of AD [15]. However, no comprehensive study to date has evaluated the potential of trace metal biomarkers in predicting cognitive decline.

We aimed to assess the potential of 36 trace elements in predicting cognitive decline in patients with $\mathrm{aMCl}$ or $\mathrm{AD}$. In addition, we used plasma levels of the trace elements to define optimal cut-off values in order to differentiate healthy elderly controls (HCs) from those with aMCl or $\mathrm{AD}$.

\section{Methods}




\section{Patients}

This cross-sectional study enrolled 40 subjects who attended the memory clinic at the Tri-Service General Hospital (TSGH) of the National Defense Medical Centre, Taiwan between January 01, 2019 and October 31,2020 . Of these subjects, there were nine healthy controls (HCs), 23 patients with aMCl and eight with AD. The inclusion criteria were as follows: (1) age $\geq 60$ years and (2) with negative results in physical and neurological examinations and laboratory tests (creatinine, fasting blood sugar, vitamin B12, folic acid, free-thyroxine 4 and high-sensitivity thyroid-stimulating hormone; serologic test for syphilis, white blood cell, red blood cell, hemoglobin, mean corpuscular volume, mean corpuscular hemoglobin, mean corpuscular hemoglobin concentration, and platelet count). We conducted brain imaging (brain computed tomography or magnetic resonance imaging) to rule out non-Alzheimer's disorders.

The exclusion criteria were as follows: (1) a history of major or uncontrolled medical diseases, such as heart failure, chronic obstructive pulmonary disease, liver cirrhosis, renal failure, sepsis, poorly controlled diabetes (Hemoglobin A1c > 8.5), myocardial infarction, or malignancy; (2) substance abuse; (3) a history of major neurological diseases, such as stroke or Parkinson's disease; (4) Geriatric Depression Scale score (short form) $>9$ or modified Rankin Scale scores $>3$; and (5) a history of major psychiatric illness that can impair cognitive function, such as major depressive disorder, bipolar disorder, or schizophrenia.

Following their written informed consent, the participants underwent Mini-Mental Status Examination (MMSE); Clinical Dementia Rating (CDR); short-form Geriatric Depression Scale (GDS-S); verbal fluency test (VFT); Hopkins Verbal Learning Test (HVLT); forward and backward digit span; Trail Making Test, Part A (TMTA); Modified Boston Naming Test (MBNT); and Hachinski Ischemia Scale (HIS). The second MMSE was performed at a 1-year follow-up.

We classified the participants into the control, aMCl, and AD groups according to the results of HVLT, MMSE, and CDR, and the recommendations of the NIA-AA workgroups on diagnostic guidelines for AD and $\mathrm{aMCl}[16,17]$. AD diagnosis was based on the following criteria: (1) NIA-AA criteria;[17] (2) CDR $\geq 0.5$; (bc MMSE $\leq 26$ (middle school), $\leq 22$ (primary school), or $\leq 19$ (illiteracy); (3) HIS $\leq 3$; and (4) HVLT $\leq 19$ [18]. In contrast, aMCl diagnosis was based on the following criteria: (1) NIA-AA criteria;[16] (2) CDR = 0.5; (3) MMSE > 26 (middle school), > 22 (primary school), or > 19 (illiteracy); (4) HIS $\leq 3$; and (5) HVLT $\leq 22$ [18]. The healthy controls were required to meet the following criteria: (1) no active neurological or psychiatric disorders; (2) no psychotropic drugs; (3) MMSE > 26 (middle school), > 22 (primary school), or $>19$ (illiteracy); and (4) CDR score $=0$. All participants or their primary caregivers signed a written informed consent form following a complete written and verbal explanation of the study. The study protocol was approved by the Institutional Review Board of the TSGH.

\section{Measuring the plasma trace elements}

We collected the venous blood in heparinized vacutainer BD tubes (Becton Dickinson Labware, Franklin Lakes, USA) and stored them at $-20^{\circ} \mathrm{C}$ until the time of analysis. We quantified the trace elements using an Agilent 7800 ICP-MS instrument (Agilent Technologies, USA). 
Prior to the analysis, $100 \mu \mathrm{L}$ blood plasma were diluted (1:50 v:v) with a diluent comprising $0.05 \%$ Triton X-100 (Sigma-Aldrich, Co., MO, USA) and 1\% HNO3 (ULTREX® 区Ultrapure Reagent, J.T.Baker, Co., Canada) in $18.2 \mathrm{M} \Omega \mathrm{cm}$ distilled deionized water.

We calibrated the system using standard solutions with different concentrations of trace elements prepared from Certipur ${ }^{\circledR}$ Certified Reference Material (Merck, Germany). We used metal solutions with a final concentration of $0.10,20,30,40$ and $50 \mu \mathrm{g} / \mathrm{L}$ for external calibration of the system. We performed a laboratory quality control via a permanent analysis of the certified reference material of blood plasma (ClinChek® Plasma/Whole Blood Control for Trace Elements, RECIPE Chemicals + Instruments GmbH, Germany).

\section{ApoE genotyping}

To obtain genetic information from samples collected from Taiwanese patients of Han Chinese ethnicity efficiently, the Taiwan Biobank (TWB) designed the TWB genotype array, based on the Affymetrix Axiom genotyping platform. The TWB genotype array enabled good-quality genotyping. Two single-nucleotide polymorphisms (SNPs, rs429358 and rs7412) defining Apo E isoforms were genotyped using the TWB array.

\section{Statistical analyses}

We compared the demographics and scores of cognitive tests between the binary study groups (i.e., aMCl vs. control; AD vs. control) using independent sample t-test and the Fisher's exact test for the continuous and categorical variables, respectively. The linear trend across the disease groups (from control, aMCI to AD) was assessed using a linear contrast in the general linear model and the Cochran-Armitage trend test for the continuous and categorical variables, respectively. Considering the lack of normality, levels of trace metals between the binary study groups were compared using the non-parametric Mann-Whitney Utest. Likewise, we evaluated the linear trend of trace metals across the disease groups using the Jonckheere-Terpstra test. In addition, we further adjusted the age for evaluating the group difference (pairwise comparison) and the trend analysis in the cognitive tests and trace metals, as the age significantly differed between the groups.

We also evaluated the utility of individual trace metals in differentiating between the disease groups (aMCl vs. control; $A D$ vs. control; and $A D$ vs. $a M C l$ ) using the area under the receiver operating characteristic (ROC) curve (AUC). The $95 \%$ confidence interval of AUC was calculated using the DeLong's method. We used the Youden index to determine the optimal cut-off value.

The trace metals with significant differentiation ability in the previous ROC analyses were selected for further analyses. The association between those trace metals and the annual change of the MMSE score ([second assessment-first assessment]/follow-up year) in either disease group (aMCl or AD) was further assessed using a partial correlation with an adjustment for the age, education level, and body mass index. All tests were two-tailed and a P-value $<0.05$ was considered statistically significant. Data analyses were conducted using SPSS 25 (IBM SPSS Inc, Chicago, Illinois). 


\section{Results}

\section{Patient profiles}

Of the total 40 subjects, nine were non-disease controls. The remaining were comprised of 23 and eight patients with $\mathrm{aMCl}$ and $\mathrm{AD}$, respectively. There was no difference in the sex distribution among the study groups. Patients in the AD group ( $82.9 \pm 8.6$ years) were the oldest, followed by those in the $\mathrm{aMCl}$ (78.3 \pm 7.8 years) and the control group $(67.0 \pm 6.3$ years) ( $P$ for trend $<0.001)$. The baseline cognitive tests were the poorest in the $\mathrm{AD}$ group, followed by the aMCl and control group ( $\mathrm{P}$ for trend $<0.05$ in the baseline MMSE and tCDR tests) (Table 1).

\section{Trace elements}

An increase in the disease severity was associated with lowered boron (B), bismuth (Bi), thorium (Th), and uranium $(U)$ levels (all of adjusted $P$ for trend $<0.05$ ) (Table 2 and Figure 1). The levels of " $\mathrm{B}$ ", "Bi", "Th", and " $U$ " were significantly different between the aMCl and control groups as well as between the $A D$ and control groups. However, the levels of "Mn", " $\mathrm{Zr}$ ", "Sb", "Ba", and " $\mathrm{Pt}$ " were only significantly different between the aMCl and control groups. In contrast, the levels of " $\mathrm{Cr}$ ", "Co", "Ge" and "T" were only significantly different between the AD and control groups (Table 2).

\section{The utility of trace metals to differentiate between the disease groups}

We evaluated the utility of trace metals in differentiating between the disease groups (aMCl vs. control; $A D$ vs. control; and $A D$ vs. aMCl). The levels of " $B$ ", " $\mathrm{Hg}$ " and "Th" could differentiate between all disease groups, including that between aMCl and $\mathrm{AD}$. In contrast, the levels of " $\mathrm{Ca}$ ", " $\mathrm{Zr}$ ", "W", "Tl", "Bi", and "U" could differentiate both $\mathrm{aMCl}$ and $\mathrm{AD}$ from the control group. In addition, the levels of " $\mathrm{B}$ ", "Mn", "Co", "Cu", "Ge", "Se", "Ba", “Pt", "Hg”, "Pb", and "Th" could distinguish between the aMCl and AD groups (Supplemental Table 1.). The optimal cut-off value of the selected trace metals with satisfying differentiation ability (AUC>70.0\%) and the corresponding sensitivity/specificity are displayed in

\section{Supplemental Table 2.}

The association between trace metals and an annual change in MMSE scores

We eventually selected the trace metals with significant differentiating ability to evaluate their association with the annual change in MMSE scores. Higher levels of "B", "Zr", and "Th" were significantly associated with a greater cognitive decline in the aMCl group. In contrast, higher levels of "Ca" were significantly associated with a less cognitive decline in the aforementioned group. Higher levels of "Mn" were associated with a greater cognitive decline in the AD group (Table 3 ). 


\section{Discussion}

This is the first clinical study to evaluate the relationship between multiple serum metal levels and cognitive decline in healthy participants as well as those with $\mathrm{aMCl}$ or $\mathrm{AD}$. The plasma concentrations of "B", "Bi", "Th", and " $\mathrm{U}$ " decreased with an increase in the disease severity. Moreover, "B", "Bi", "Th", and " $\mathrm{U}$ " levels were significantly different between patients with $\mathrm{aMCl}$ as well as $A D$ and the healthy controls. The ROC analyses revealed that the plasma concentrations of " $\mathrm{B}$ ", " $\mathrm{Hg}$ ", and " $\mathrm{Th}$ " could differentiate between the disease groups (aMCl vs. control; $A D$ vs. control; and $A D$ vs. $a M C l$ ). " $B$ " demonstrated high AUCs for aMCl versus the controls $(97.6 \%$, cut-off value: $\leq 73.1 \mathrm{ug} / \mathrm{l})$ and $A D$ versus the controls $(100 \%$, cut-off value: $\leq 47.1 \mathrm{ug} / \mathrm{l})$. " $\mathrm{Hg}$ " revealed the highest AUC to differentiate AD from aMCl $(79.9 \%$, cut-off value: $\leq 1.02 \mathrm{ug} / \mathrm{l})$. Following an adjustment for the potential confounding factors in the aMCl group, while higher baseline levels of " $\mathrm{Ca}$ " were associated with a smaller cognitive decline, those of " $\mathrm{B}$ ", " $\mathrm{Zr}$ ", and " $\mathrm{Th}$ " were associated with a rapid cognitive decline. In contrast, higher baseline levels of "Mn" were associated with a rapid cognitive decline in the $A D$ group.

" $B$ " levels were negatively associated with $\mathrm{aMCl}$ and $A D$. " $B$ " is an essential trace element, abundant in fruits, vegetables, walnuts, and pulses. Recent animal and human studies have reported that long-term dietary supplementation with walnuts may reduce the risk or delay the progression of aMCl and $A D[19$, 20]. There is increasing evidence for the beneficial effects of " $B$ " on human health, particularly in promoting hormone and immune response, inflammation, oxidative stress regulation, and central nervous system function [21]. Furthermore, "B" deprivation leads to poor performance in tasks, such as movement speed and flexibility, attention, and short-term memory in older adults [22]. In other words, the aforementioned studies highlight an association between " $B$ " levels and cognitive function. In addition, "B" plays an important role in human brain function and cognitive protection.

The plasma "Th" levels were negatively associated with $\mathrm{aMCl}$ and $\mathrm{AD}$. Moreover, higher baseline levels of "Th" were associated with a faster cognitive decline. An animal study reported that "Th"-treated mice demonstrated impaired learning and memory performance, similar to our results [23]. Furthermore, it resulted in the activation of acetylcholinesterase in mouse brain [23]. This necessitates further research on humans to reveal the underlying association between "Th" and cognitive function.

The plasma " $\mathrm{U}$ " concentrations were negatively associated with aMCI and $\mathrm{AD}$. Daily dietary intake as well as water consumption are the most common ways of ingesting " $U$ ". Root crops, such as potatoes and sweet potatoes contribute the highest " $U$ " content in the diet [24]. Moreover, sweet potato anthocyanins can enhance memory and improve cognitive deficits, which in turn may be related to its antioxidant properties $[25,26]$.

Higher baseline levels of "Ca" were associated with less cognitive decline in patients with aMCl. A longitudinal population-based study from Sweden revealed that women receiving "Ca" supplements are at higher risk of developing dementia (odds ratio, 2.10; $p=0.046$ ) [27]. Moreover, according to the unadjusted trend analysis in mixed-gender groups, "Ca" levels were lowest in the healthy control group and highest in the aMCl and $\mathrm{AD}$ groups. Recent studies have reported on the association between the 
disruption of intracellular $\mathrm{Ca} 2+$ homeostasis and the neuropathology of $\mathrm{AD}$, memory loss, and cognitive dysfunction $[28,29]$. Increased intracellular " $\mathrm{Ca}$ " in the endoplasmic reticulum (ER) is the possible mechanism by which presenilin mutations disrupt intracellular " $\mathrm{Ca}$ " signaling. Furthermore, preclinical studies have revealed that excess ER Ca2 + release through the inositol 1,4,5-trisphosphate receptor or the ryanodine receptor is related to tau and amyloid pathology, and contributes to memory and learning deficits $[30,31]$. Therefore, calcium dyshomeostasis plays a critical role in the pathogenesis of AD.

We observed an inverse association between " $\mathrm{Hg}$ " levels and both $\mathrm{aMCl}$ and $\mathrm{AD}$. There are three major groups of " $\mathrm{Hg}$ " compounds, namely elemental, inorganic, and organic. " $\mathrm{Hg}$ " is converted to methylmercury by bacteria, which enters the food chain and bioaccumulates in predatory fish [32]. Fish consumption is the primary source of methylmercury exposure [32]. Seafood, including shellfish and finfish is the largest contributor to organic " $\mathrm{Hg}$ " exposure in the human population. A systemic review mentioned that long-chain omega-3 fatty acids in a high-fish diet can delay cognitive decline in elderly individuals, without dementia [33]. The serum " $\mathrm{Hg}$ " levels of our subjects was within the normal range, thus indicating a normal dietary intake (normal value: $<20 \mu \mathrm{g} / \mathrm{L}$ for women aged $\geq 50$ years and men aged $>18$ years) [34]. Nonetheless, ICP-MS can only detect total " $\mathrm{Hg}$ " and fails to distinguish between the organic and inorganic forms. However, patients with $\mathrm{aMCl}$ or $\mathrm{AD}$ may likely reduce their seafood intake, thereby reducing organic methylmercury exposure, compared to healthy controls. We did not use a detailed food frequency questionnaire, including the types, frequency, and amount of seafood intake. This made it difficult to explain the inverse correlation between " $\mathrm{Hg}$ " levels and $\mathrm{aMCl}$ and $\mathrm{AD}$, thus necessitating further investigation.

Our study established an association between higher baseline levels of " $\mathrm{Mn}$ " and rapid annual cognitive decline in patients with $A D$. "Mn" is an essential metal that maintains the normal functions of the human body. However, increased " $M \mathrm{n}$ " levels in the brain are associated with impaired motor coordination, memory deficits, psychiatric disorders, and Parkinson's disease [35-37]. An animal study reported that the overexpression of $A \beta$ in transgenic mice lead to " $M n$ " accumulation in the brain, thus suggesting the role of A $\beta$ may in "Mn" homeostasis and neurotoxicity [38]. A study conducted in China further mentioned that people with higher plasma "Mn" concentrations were associated with higher plasma A $\beta$ peptides levels, similar to our results [39]. The aforementioned evidences suggested a relationship between " $M n^{\prime \prime}$ and $A D$, and the presence of shared pathophysiological mechanisms.

The strengths of our study include the robust statistical analysis, detailed cognitive examinations, prospective design, and large response rate at follow-up. However, our study had some limitations, which should be considered while interpreting the findings. First, the NIA-AA research framework defines AD as a biological construct rather a clinical diagnosis. However, AD diagnosis focuses on the biomarkers of brain $A \beta$ deposition, pathologic tau, and neurodegeneration [8]. Our study population was limited to clinically evaluated patients with positive results for the cognitive tests. Moreover, we did not obtain amyloid and Tau positron emission tomography scans nor any CSF biomarkers. Second, cognitive decline is closely related to neurodegenerative biomarkers, such as hippocampal atrophy [40]. The pathophysiological link between the trace metals and neurodegenerative biomarkers remains to be 
determined. Third, the participants were recruited in a tertiary medical center. Therefore, our results may not be generalized to other populations, such as elderly people living in the community. However, there was also some strength of the single-center design, which made it possible to systematically and uniformly collect all the data of all participants. In addition, the cognitive assessment conducted by the board-certified clinical psychologist, making information bias less likely. Fourth, our sample size was small. Therefore, our findings need to be verified by large-scale studies in future. Fifth, we only measured the metals at a single time point, which may reflect a short period of exposure. Therefore, long-term serial measurements of trace metals may help researchers explore their relationship with cognitive decline.

\section{Conclusions}

This was the first exploratory study to compare the differentiating ability of trace elements biomarkers in patients with $\mathrm{aMCl}$ and $\mathrm{AD}$. Several trace elements were significantly associated with the abovementioned cognitive tests and annual cognitive changes in the patients. The plasma concentrations of "B", " $\mathrm{Hg}$ ", and "Th" could satisfactorily detect different stages of cognitive function in healthy controls and patients with aMCl and $\mathrm{AD}$. Moreover, higher baseline levels of " $\mathrm{B}$ ", " $\mathrm{Zr}$ ", and " $\mathrm{Th}$ " and " $\mathrm{Mn}$ " were associated with a rapid cognitive decline in patients with $\mathrm{aMCl}$ and $\mathrm{AD}$, respectively. Further large-scale longitudinal studies are required to replicate our preliminary findings.

\section{Abbreviations}

$A D$

Alzheimer's disease; aMCl:amnestic mild cognitive impairment; NIA-AA:The National Institute on Aging and Alzheimer's Association; A $\beta$ : $\beta$-amyloid; PET:positron emission tomography; MRI:magnetic resonance imaging; CSF:cerebrospinal fluid; GDS-S:Geriatric Depression Scale; MMSE:Mini-Mental State Examination; CDR:Clinical Dementia Rating; HVLT:Hopkins Verbal Learning Test; HIS:Hachinski Ischemia Scale; and ICP-MS:inductively coupled plasma-mass spectrometry

\section{Declarations}

Declarations of interest: none.

\section{Funding}

This study was supported by grants from the Ministry of Science and Technology of Taiwan (MOST 1082314-B-016-023-, MOST 108-2314-B-016-020), Tri-Service General Hospital (TSGH-C108-100, TSGH-C108216, TSGH-D-109-101, TSGH-D-109-185, TSGH-D-110048) 


\section{Ethics approval and consent to participate}

The protocol was approved by the Institutional Review Board for the Protection of Human Subjects at the Tri-Service General Hospital (TSGHIRB 1-107-05-111). Written informed consent was obtained from all participants.

\section{Consent for publication}

All authors have approved of the manuscript and agree with its submission.

\section{Availability of data and materials}

The datasets during and/or analyzed during the current study available from the corresponding author upon reasonable request.

\section{Competing interests}

All authors declare that they have no competing interests.

\section{Authors' contributions}

All authors have contributed substantially to, and are in agreement with the content of, the manuscript. Conception/design, provision of study materials, and the collection and/or assembly of data: YKL and FCY; data analysis and interpretation: all authors; manuscript preparation: all authors; and the final approval of the manuscript: all authors. The guarantor of the paper takes responsibility for the integrity of the work as a whole, from its inception to publication.

\section{Acknowledgements}

We thank Mr. Sheng-Hui Tang for assisting us with the inductively coupled plasma (ICP-MS) analysis technology, provided by the Trace Element Research Center of Tri-service General Hospital. We thank RueiYi Chao for performing neuropsychological assessments during the study period. The study was conducted using resources from Taiwan Biobank and Biobank, Tri-Service General Hospital.

\section{References}


1. Burns A, Iliffe S. Alzheimer's disease. Bmj. 2009;338:b158.

2. Dickerson BC, McGinnis SM, Xia C, Price BH, Atri A, Murray ME, et al. Approach to atypical Alzheimer's disease and case studies of the major subtypes. CNS Spectr. 2017;22:439-49.

3. Petersen RC, Negash S. Mild cognitive impairment: an overview. CNS Spectr. 2008;13:45-53.

4. Gauthier S, Reisberg B, Zaudig M, Petersen RC, Ritchie K, Broich K, et al. Mild cognitive impairment. Lancet. 2006;367:1262-70.

5. Petersen RC, Lopez O, Armstrong MJ, Getchius TSD, Ganguli M, Gloss D, et al. Practice guideline update summary: Mild cognitive impairment: Report of the Guideline Development, Dissemination, and Implementation Subcommittee of the American Academy of Neurology. Neurology. 2018;90:126-35.

6. Grundman M, Petersen RC, Ferris SH, Thomas RG, Aisen PS, Bennett DA, et al. Mild cognitive impairment can be distinguished from Alzheimer disease and normal aging for clinical trials. Arch Neurol. 2004;61:59-66.

7. Sperling RA, Aisen PS, Beckett LA, Bennett DA, Craft S, Fagan AM, et al. Toward defining the preclinical stages of Alzheimer's disease: recommendations from the National Institute on AgingAlzheimer's Association workgroups on diagnostic guidelines for Alzheimer's disease. Alzheimer's dementia: the journal of the Alzheimer's Association. 2011;7:280-92.

8. Jack CR Jr, Bennett DA, Blennow K, Carrillo MC, Dunn B, Haeberlein SB, et al. NIA-AA Research Framework: Toward a biological definition of Alzheimer's disease. Alzheimer's dementia: the journal of the Alzheimer's Association. 2018;14:535-62.

9. Dubois B, Feldman HH, Jacova C, Hampel H, Molinuevo JL, Blennow K, et al. Advancing research diagnostic criteria for Alzheimer's disease: the IWG-2 criteria. Lancet Neurol. 2014;13:614-29.

10. Herukka SK, Simonsen AH, Andreasen N, Baldeiras I, Bjerke M, Blennow K, et al. Recommendations for cerebrospinal fluid Alzheimer's disease biomarkers in the diagnostic evaluation of mild cognitive impairment. Alzheimer's dementia: the journal of the Alzheimer's Association. 2017;13:285-95.

11. Adlard PA, Bush Al. Metals and Alzheimer's disease. J Alzheimers Dis. 2006;10:145-63.

12. Duce JA, Bush Al. Biological metals and Alzheimer's disease: implications for therapeutics and diagnostics. Prog Neurobiol. 2010;92:1-18.

13. Adlard PA, Bush Al. Metals and Alzheimer's Disease: How Far Have We Come in the Clinic? J Alzheimers Dis. 2018;62:1369-79.

14. Atwood CS, Huang X, Moir RD, Tanzi RE, Bush Al. Role of free radicals and metal ions in the pathogenesis of Alzheimer's disease. Met lons Biol Syst. 1999;36:309-64.

15. Kenche VB, Barnham KJ. Alzheimer's disease \& metals: therapeutic opportunities. Br J Pharmacol. 2011;163:211-9.

16. Albert MS, DeKosky ST, Dickson D, Dubois B, Feldman HH, Fox NC, et al. The diagnosis of mild cognitive impairment due to Alzheimer's disease: recommendations from the National Institute on 
Aging-Alzheimer's Association workgroups on diagnostic guidelines for Alzheimer's disease. Alzheimer's dementia: the journal of the Alzheimer's Association. 2011;7:270-9.

17. McKhann GM, Knopman DS, Chertkow H, Hyman BT, Jack CR Jr, Kawas CH, et al. The diagnosis of dementia due to Alzheimer's disease: recommendations from the National Institute on AgingAlzheimer's Association workgroups on diagnostic guidelines for Alzheimer's disease. Alzheimer's dementia: the journal of the Alzheimer's Association. 2011;7:263-9.

18. Shi J, Tian J, Wei M, Miao Y, Wang Y. The utility of the Hopkins Verbal Learning Test (Chinese version) for screening dementia and mild cognitive impairment in a Chinese population. BMC Neurol. 2012;12:136.

19. Muthaiyah B, Essa MM, Lee M, Chauhan V, Kaur K, Chauhan A. Dietary supplementation of walnuts improves memory deficits and learning skills in transgenic mouse model of Alzheimer's disease. $\mathrm{J}$ Alzheimers Dis. 2014;42:1397-405.

20. Arab L, Ang A. A cross sectional study of the association between walnut consumption and cognitive function among adult US populations represented in NHANES. J Nutr Health Aging. 2015;19:284-90.

21. Nielsen F, Meacham S. Growing Evidence for Human Health Benefits of Boron. Complementary Health Practice Review. 2011;16:169-80.

22. Penland JG. The importance of boron nutrition for brain and psychological function. Biol Trace Elem Res. 1998;66:299-317.

23. Kumar A, Ali M, Mishra P, Pandey BN, Sharma P, Mishra KP. Thorium-induced neurobehavioural and neurochemical alterations in Swiss mice. Int J Radiat Biol. 2009;85:338-47.

24. Authority EFS. Uranium in foodstuffs, in particular mineral water. EFSA Journal. 2009;7:1018.

25. Cho J, Kang JS, Long PH, Jing J, Back Y, Chung KS. Antioxidant and memory enhancing effects of purple sweet potato anthocyanin and cordyceps mushroom extract. Arch Pharm Res. 2003;26:8215.

26. Shan Q, Lu J, Zheng Y, Li J, Zhou Z, Hu B, et al. Purple sweet potato color ameliorates cognition deficits and attenuates oxidative damage and inflammation in aging mouse brain induced by $\mathrm{d}$ galactose. J Biomed Biotechnol. 2009;2009:564737-.

27. Kern J, Kern S, Blennow K, Zetterberg H, Waern M, Guo X, et al. Calcium supplementation and risk of dementia in women with cerebrovascular disease. Neurology. 2016;87:1674-80.

28. Wang Y, Shi Y, Wei H. Calcium Dysregulation in Alzheimer's Disease: A Target for New Drug Development. J Alzheimers Dis Parkinsonism. 2017;7:374.

29. LaFerla FM. Calcium dyshomeostasis and intracellular signalling in Alzheimer's disease. Nature reviews Neuroscience. 2002;3:862-72.

30. Peng J, Liang G, Inan S, Wu Z, Joseph DJ, Meng Q, et al. Dantrolene ameliorates cognitive decline and neuropathology in Alzheimer triple transgenic mice. Neurosci Lett. 2012;516:274-9.

31. Wu Z, Yang B, Liu C, Liang G, Eckenhoff MF, Liu W, et al. Long-term dantrolene treatment reduced intraneuronal amyloid in aged Alzheimer triple transgenic mice. Alzheimer Dis Assoc Disord. 
2015;29:184-91.

32. Hellberg R, Nettleton J, Morrissey M. A Review of Mercury in Seafood. Journal of Aquatic Food Product Technology - J AQUAT FOOD PROD TECHNOL. 2005;14:71-100.

33. Fotuhi M, Mohassel P, Yaffe K. Fish consumption, long-chain omega-3 fatty acids and risk of cognitive decline or Alzheimer disease: a complex association. Nature clinical practice Neurology. 2009;5:140-52.

34. Kales SN, Thompson AMS. A young woman concerned about mercury. CMAJ: Canadian Medical Association journal = journal de l'Association medicale canadienne. 2016;188:133-4.

35. Avila DS, Puntel RL, Aschner M. Manganese in health and disease. Met lons Life Sci. 2013;13:199227.

36. Ye Q, Kim J. Effect of olfactory manganese exposure on anxiety-related behavior in a mouse model of iron overload hemochromatosis. Environ Toxicol Pharmacol. 2015;40:333-41.

37. Chen P, Chakraborty S, Mukhopadhyay S, Lee E, Paoliello MM, Bowman AB, et al. Manganese homeostasis in the nervous system. J Neurochem. 2015;134:601-10.

38. Maynard CJ, Cappai R, Volitakis I, Cherny RA, White AR, Beyreuther K, et al. Overexpression of Alzheimer's disease amyloid-beta opposes the age-dependent elevations of brain copper and iron. $J$ Biol Chem. 2002;277:44670-6.

39. Tong $Y$, Yang H, Tian X, Wang H, Zhou T, Zhang S, et al. High manganese, a risk for Alzheimer's disease: high manganese induces amyloid- $\beta$ related cognitive impairment. J Alzheimers Dis. 2014;42:865-78.

40. Jack CR Jr, Knopman DS, Jagust WJ, Petersen RC, Weiner MW, Aisen PS, et al. Tracking pathophysiological processes in Alzheimer's disease: an updated hypothetical model of dynamic biomarkers. Lancet Neurol. 2013;12:207-16.

\section{Tables}

Table 1. Baseline characteristics of the 40 enrolled participants according to disease group $^{\mathrm{a}}$ 


\begin{tabular}{|c|c|c|c|c|c|c|}
\hline \multirow[b]{2}{*}{ Variable } & \multirow{2}{*}{$\begin{array}{l}\text { Control } \\
(n=9)\end{array}$} & \multirow{2}{*}{$\begin{array}{c}\text { aMCI } \\
(n=23)\end{array}$} & \multirow{2}{*}{$\begin{array}{c}\mathrm{AD} \\
(n=8)\end{array}$} & \multicolumn{3}{|c|}{$P$ value \# } \\
\hline & & & & $\begin{array}{c}P \\
\text { trend }\end{array}$ & $\begin{array}{l}\text { aMCI vs. } \\
\text { Control }\end{array}$ & $\begin{array}{l}\text { AD vs. } \\
\text { Control }\end{array}$ \\
\hline \multicolumn{7}{|l|}{ Demographics } \\
\hline Male & $3(33.3)$ & $4(17.4)$ & $2(25.0)$ & 0.652 & 0.297 & 0.563 \\
\hline Age, years & $\begin{array}{l}67.0 \pm \\
6.3\end{array}$ & $78.3 \pm 7.8$ & $82.9 \pm 8.6$ & $<0.001$ & 0.001 & 0.001 \\
\hline Education, years & $\begin{array}{l}10.9 \pm \\
3.8\end{array}$ & $7.3 \pm 4.7$ & $9.5 \pm 5.1$ & 0.498 & 0.048 & 0.529 \\
\hline $\begin{array}{l}\text { Body mass index, } \\
\mathrm{kg} / \mathrm{m}^{2}\end{array}$ & $\begin{array}{l}23.4 \pm \\
2.4\end{array}$ & $25.2 \pm 4.0$ & $23.8 \pm 3.9$ & 0.778 & 0.133 & 0.796 \\
\hline \multicolumn{7}{|l|}{ Cognitive test } \\
\hline Baseline MMSE & $\begin{array}{l}29.3 \pm \\
0.5\end{array}$ & $23.9 \pm 3.7$ & $19.5 \pm 7.7$ & 0.043 & 0.250 & 0.141 \\
\hline tCDR & $0.4 \pm 0.3$ & $1.7 \pm 1.1$ & $5.1 \pm 4.0$ & 0.011 & 0.776 & 0.106 \\
\hline HVLT & $\begin{array}{l}22.0 \pm \\
5.2\end{array}$ & $16.0 \pm 4.9$ & $13.0 \pm 6.7$ & 0.211 & 0.277 & 0.341 \\
\hline Disease Index & $\begin{array}{l}11.1 \pm \\
0.8\end{array}$ & $9.9 \pm 1.8$ & $7.5 \pm 4.6$ & 0.098 & 0.850 & 0.240 \\
\hline fDS & $\begin{array}{c}11.2 \pm \\
1.6\end{array}$ & $8.3 \pm 2.8$ & $8.6 \pm 3.0$ & 0.985 & 0.144 & 0.970 \\
\hline bDS & $6.9 \pm 3.0$ & $4.1 \pm 3.0$ & $3.1 \pm 2.4$ & 0.512 & 0.526 & 0.532 \\
\hline VFT & $\begin{array}{l}14.3 \pm \\
2.2\end{array}$ & $11.0 \pm 4.2$ & $6.1 \pm 3.2$ & 0.059 & 0.860 & 0.073 \\
\hline MBNT & $\begin{array}{c}14.3 \pm \\
0.9\end{array}$ & $13.1 \pm 1.5$ & $12.4 \pm 2.3$ & 0.185 & 0.188 & 0.251 \\
\hline TMTA & $\begin{array}{l}53.9 \pm \\
27.7\end{array}$ & $\begin{array}{c}136.2 \pm \\
98.8\end{array}$ & $\begin{array}{c}179.9 \pm \\
110.4\end{array}$ & 0.315 & 0.318 & 0.304 \\
\hline $\begin{array}{l}\text { Apolipoprotein } \\
\text { E } \varepsilon 2: \varepsilon 3: \varepsilon 4\end{array}$ & $2: 15: 1$ & $2: 37: 7$ & $1: 11: 4$ & & 0.382 & 0.267 \\
\hline
\end{tabular}

Abbreviations: aMCI, amnestic mild cognitive impairment; AD, Alzheimer's disease; MMSE, Mini-Mental Status Examination; tCDR, total score of Clinical Dementia Rating; HVLT, Hopkins Verbal Learning Test; fDS, forward digit span; bDS, backward digit span; VFT, verbal fluency test; MBNT, Modified Boston Naming Test; TMTA, Trail Making Test Part A. a Data are expressed as mean \pm standard deviation. \# The analysis was adjusted for age, except the four demographics factors.

Table 2. Trace metals of the enrolled participants according to disease group ${ }^{\mathrm{a}}$ 


\section{Control}

aMCI

$\mathrm{AD}$

$P$ value \#

Variable

\begin{tabular}{|c|c|c|c|c|c|c|}
\hline $\begin{array}{l}\mathrm{Li} \\
\mathrm{Be}\end{array}$ & $\begin{array}{c}1.07[0.73 \\
1.11] \\
0.92[0.50 \\
0.98]\end{array}$ & $\begin{array}{c}1.21[1.01 \\
1.70] \\
0.61[0.51 \\
1.49]\end{array}$ & $\begin{array}{c}1.35[0.73 \\
1.61] \\
0.64[0.40 \\
1.15]\end{array}$ & $\begin{array}{l}0.989 \\
0.474\end{array}$ & $\begin{array}{l}0.414 \\
0.722\end{array}$ & $\begin{array}{l}0.847 \\
0.564\end{array}$ \\
\hline B & $141[106,160]$ & $53[24,71]$ & $35[12,45]$ & 0.005 & 0.009 & 0.012 \\
\hline $\mathrm{Al}$ & $\begin{array}{c}18.0[15.0 \\
19.6]\end{array}$ & $\begin{array}{c}14.5[11.1 \\
17.9]\end{array}$ & $\begin{array}{c}14.5[13.2, \\
19.7]\end{array}$ & 0.299 & 0.950 & 0.248 \\
\hline $\begin{array}{l}\mathrm{Ca} \\
(1 / 1000)\end{array}$ & $\begin{array}{l}86.5[84.6 \\
88.5]\end{array}$ & $\begin{array}{l}93.1[88.2, \\
99.1]\end{array}$ & $\begin{array}{l}93.1[89.0, \\
97.1]\end{array}$ & 0.291 & 0.173 & 0.441 \\
\hline $\mathrm{V}$ & $\begin{array}{c}0.29[0.18 \\
0.33]\end{array}$ & $\begin{array}{c}0.21[0.13 \\
0.26]\end{array}$ & $\begin{array}{c}0.22[0.17 \\
0.26]\end{array}$ & 0.477 & 0.201 & 0.564 \\
\hline $\mathrm{Cr}$ & $1.4[1.2,1.5]$ & $1.5[1.2,4.4]$ & $1.5[1.0,1.6]$ & 0.552 & 0.414 & 0.043 \\
\hline $\mathrm{Mn}$ & $\begin{array}{c}0.89[0.78 \\
1.01]\end{array}$ & $\begin{array}{c}1.48[0.46 \\
2.26]\end{array}$ & $\begin{array}{c}0.21[0.00 \\
0.64]\end{array}$ & 0.947 & 0.028 & 0.773 \\
\hline $\mathrm{Fe}$ & $987[904,1140]$ & $\begin{array}{c}1360[952, \\
1654]\end{array}$ & $\begin{array}{c}1316[987 \\
1708]\end{array}$ & 0.468 & 0.201 & 0.386 \\
\hline Co & $\begin{array}{c}0.15[0.13 \\
0.17]\end{array}$ & $\begin{array}{c}0.17[0.15 \\
0.27]\end{array}$ & $\begin{array}{c}0.23[0.19 \\
0.41]\end{array}$ & 0.067 & 0.267 & 0.027 \\
\hline $\mathrm{Ni}$ & $\begin{array}{c}0.66[0.45 \\
0.99]\end{array}$ & $\begin{array}{c}0.91[0.69 \\
1.56]\end{array}$ & $\begin{array}{l}0.63[0.45 \\
1.09]\end{array}$ & 0.821 & 0.107 & 1.000 \\
\hline $\mathrm{Cu}$ & $832[693,915]$ & $956[850,1090]$ & $788[743,977]$ & 0.625 & 0.090 & 0.564 \\
\hline $\mathrm{Zn}$ & $780[633,842]$ & $751[679,802]$ & $740[690,830]$ & 0.706 & 0.883 & 0.630 \\
\hline $\mathrm{Ga}$ & $\begin{array}{c}0.071[0.047 \\
0.095]\end{array}$ & $\begin{array}{c}0.059[0.024 \\
0.071]\end{array}$ & $\begin{array}{c}0.036[0.035 \\
0.036]\end{array}$ & 0.102 & 0.173 & 0.248 \\
\hline $\mathrm{Ge}$ & $\begin{array}{c}0.00[0.00 \\
0.02]\end{array}$ & $\begin{array}{c}0.00[0.00 \\
0.04]\end{array}$ & $\begin{array}{c}0.00[0.00 \\
0.00]\end{array}$ & 0.348 & 0.216 & 0.002 \\
\hline As & $4.9[4.3,9.4]$ & $5.7[4.7,10.3]$ & $5.5[4.6,8.8]$ & 0.541 & 0.600 & 0.700 \\
\hline Se & $171[158,183]$ & $175[158,191]$ & $148[141,167]$ & 0.368 & 0.414 & 0.124 \\
\hline $\mathrm{Rb}$ & $216[209,250]$ & $219[193,243]$ & $206[162,252]$ & 0.599 & 0.917 & 0.700 \\
\hline $\mathrm{Sr}$ & $\begin{array}{c}30.0[26.9 \\
35.1]\end{array}$ & $\begin{array}{c}34.9[27.9 \\
43.9]\end{array}$ & $\begin{array}{c}35.6[32.4 \\
39.4]\end{array}$ & 0.265 & 0.304 & 0.102 \\
\hline $\mathrm{Zr}$ & $\begin{array}{l}1.68[1.61 \\
2.58]\end{array}$ & $\begin{array}{c}0.50[0.37 \\
0.70]\end{array}$ & $\begin{array}{c}0.41[0.25 \\
0.72]\end{array}$ & 0.066 & 0.034 & 0.248 \\
\hline Mo & $2.0[1.0,2.0]$ & $2.1[1.3,2.8]$ & $1.7[1.2,2.9]$ & 0.932 & 0.753 & 0.441 \\
\hline $\mathrm{Ag}$ & $\begin{array}{c}0.02[0.00 \\
0.29]\end{array}$ & $\begin{array}{c}0.03[0.00 \\
0.13]\end{array}$ & $\begin{array}{c}0.07[0.00 \\
0.21]\end{array}$ & 0.514 & 0.867 & 0.700 \\
\hline $\mathrm{Cd}$ & $\begin{array}{c}0.07[0.04 \\
0.07]\end{array}$ & $\begin{array}{c}0.07[0.05 \\
0.14]\end{array}$ & $\begin{array}{c}0.06[0.04 \\
0.07]\end{array}$ & 0.499 & 0.630 & 0.386 \\
\hline Sn & $\begin{array}{c}0.00[0.00 \\
0.59]\end{array}$ & $\begin{array}{c}0.00[0.00 \\
0.12]\end{array}$ & $\begin{array}{c}0.00[0.00 \\
0.00]\end{array}$ & 0.978 & 0.216 & 0.500 \\
\hline $\mathrm{Sb}$ & $8.0[7.4,10.6]$ & $7.0[6.1,7.7]$ & $6.5[6.1,7.8]$ & 0.159 & 0.038 & 0.211 \\
\hline $\mathrm{Te}$ & $\begin{array}{c}0.00[0.00 \\
0.00]\end{array}$ & $\begin{array}{c}0.00[0.00 \\
0.26]\end{array}$ & $\begin{array}{c}0.00[0.00 \\
0.00]\end{array}$ & 0.802 & 0.232 & 0.027 \\
\hline $\mathrm{Ba}$ & $0.8[0.8,1.4]$ & $1.0[0.7,1.4]$ & $0.6[0.5,0.9]$ & 0.765 & 0.022 & 0.211 \\
\hline W & $\begin{array}{c}95.4[33.0 \\
230.3]\end{array}$ & $0.0[0.0,0.0]$ & $0.0[0.0,0.0]$ & 0.071 & 0.173 & 0.563 \\
\hline $\mathrm{Pt}$ & $\begin{array}{l}0.00[0.00 \\
0.00]\end{array}$ & $\begin{array}{l}0.02[0.00 \\
0.03]\end{array}$ & $\begin{array}{c}0.00[0.00 \\
0.00]\end{array}$ & 0.459 & 0.038 & 0.149 \\
\hline $\mathrm{Au}$ & $4.2[1.9,35.6]$ & $0.0[0.0,0.0]$ & $0.0[0.0,0.0]$ & 0.211 & 0.516 & 0.290 \\
\hline $\mathrm{Hg}$ & $3.2[2.2,7.0]$ & $1.8[1.2,2.2]$ & $0.8[0.6,1.2]$ & 0.102 & 0.850 & 0.700 \\
\hline $\mathrm{Tl}$ & $\begin{array}{c}0.052[0.033 \\
0.072]\end{array}$ & $\begin{array}{c}0.028[0.018 \\
0.044]\end{array}$ & $\begin{array}{c}0.014[0.010 \\
0.037]\end{array}$ & 0.073 & 0.126 & 0.124 \\
\hline
\end{tabular}


Control

aMCI

$\mathrm{AD}$

$P$ value \#

Variable

$\mathrm{Pb} \quad 0.18[0.17$, $0.42]$

$1.47[0.23$, $1.97]$

\section{$\mathrm{AD}$}

$03[0.02$,
$0.04]$

$0.43[0.00$, $1.14]$

$\mathrm{Bi}$
$0.06]$
$0.05[0.04$,

$4.0[2.9,7.1]$

Th

U

0.017 [0.014,

0.023 ]

$0.0[0.0,0.5]$

$0.02[0.01$
$0.03]$

$\begin{array}{cccc}0.0[0.0,0.0] & 0.005 & 0.002 & 0.043 \\ 0.007[0.005, & 0.048 & 0.034 & 0.005 \\ 0.015] & & & \end{array}$

Abbreviations: aMCI, amnestic mild cognitive impairment; AD, Alzheimer's disease; NA, not applicable;

a Data are expressed as median [1st quartile, 3rd quartile].

\# The analysis was adjusted for age;

Table 3. Association between trace metals and annual change of MMSE*

\begin{tabular}{lcccc}
\hline & \multicolumn{2}{c}{ aMCI } & & \multicolumn{2}{c}{ AD } \\
\cline { 2 - 2 } \cline { 5 - 5 } Trace metal & Partial correlation\# & $P$ value & & Partial correlation\# $P$ value \\
\hline $\mathrm{B}$ & -0.70 & 0.001 & -0.03 & 0.967 \\
\hline $\mathrm{Al}$ & -0.09 & 0.707 & -0.01 & 0.982 \\
$\mathrm{Ca}$ & $\mathbf{0 . 5 0}$ & $\mathbf{0 . 0 2 6}$ & -0.82 & 0.092 \\
$\mathrm{Mn}$ & -0.35 & 0.133 & -0.91 & $\mathbf{0 . 0 3 5}$ \\
$\mathrm{Co}$ & -0.25 & 0.296 & -0.37 & 0.545 \\
$\mathrm{Cu}$ & -0.11 & 0.646 & -0.44 & 0.454 \\
$\mathrm{Ga}$ & 0.10 & 0.676 & -0.04 & 0.948 \\
$\mathrm{Ge}$ & -0.03 & 0.889 & $\mathrm{NA}$ & $\mathrm{NA}$ \\
$\mathrm{Se}$ & 0.20 & 0.405 & 0.35 & 0.560 \\
$\mathrm{Zr}$ & -0.58 & $\mathbf{0 . 0 0 7}$ & -0.50 & 0.389 \\
$\mathrm{Sb}$ & 0.13 & 0.594 & 0.71 & 0.178 \\
$\mathrm{Ba}$ & -0.25 & 0.298 & -0.45 & 0.449 \\
$\mathrm{~W}$ & -0.30 & 0.194 & $\mathrm{NA}$ & $\mathrm{NA}$ \\
$\mathrm{Au}$ & $\mathrm{NA}$ & $\mathrm{NA}$ & $\mathrm{NA}$ & $\mathrm{NA}$ \\
$\mathrm{Hg}$ & 0.23 & 0.338 & -0.40 & 0.508 \\
$\mathrm{Tl}$ & -0.42 & 0.064 & 0.14 & 0.823 \\
\hline $\mathrm{Pb}$ & -0.13 & 0.593 & -0.80 & 0.108 \\
$\mathrm{Bi}$ & -0.11 & 0.657 & 0.64 & 0.250 \\
\hline $\mathrm{Th}$ & -0.52 & $\mathbf{0 . 0 2 0}$ & $\mathrm{NA}$ & $\mathrm{NA}$ \\
$\mathrm{U}$ & 0.04 & 0.885 & 0.74 & 0.156 \\
\hline
\end{tabular}

Abbreviations: MMSE, Mini-Mental Status Examination; aMCI, amnestic mild cognitive impairment; $\mathrm{AD}$, Alzheimer's disease; NA, not applicable;

\# Adjusted for age, education level and body mass index;

* defined as ([the second assessment - the first assessment] / follow up year). 
Figures

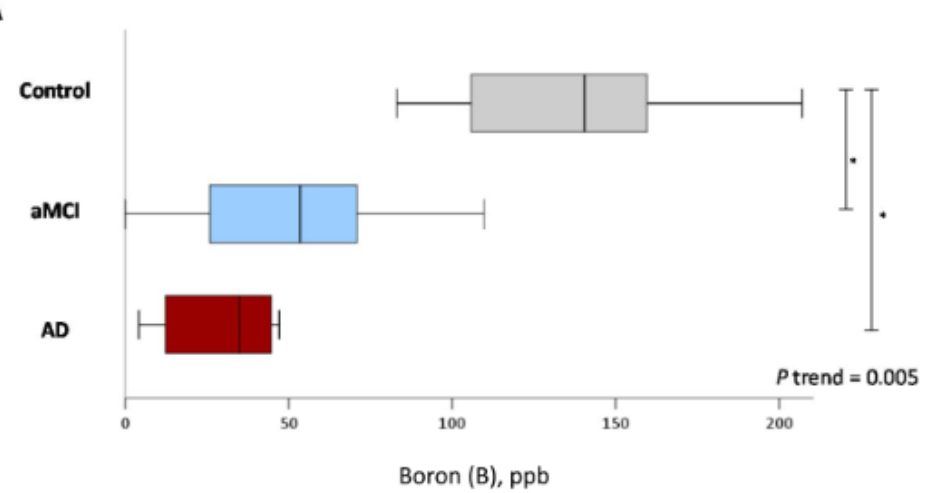

C

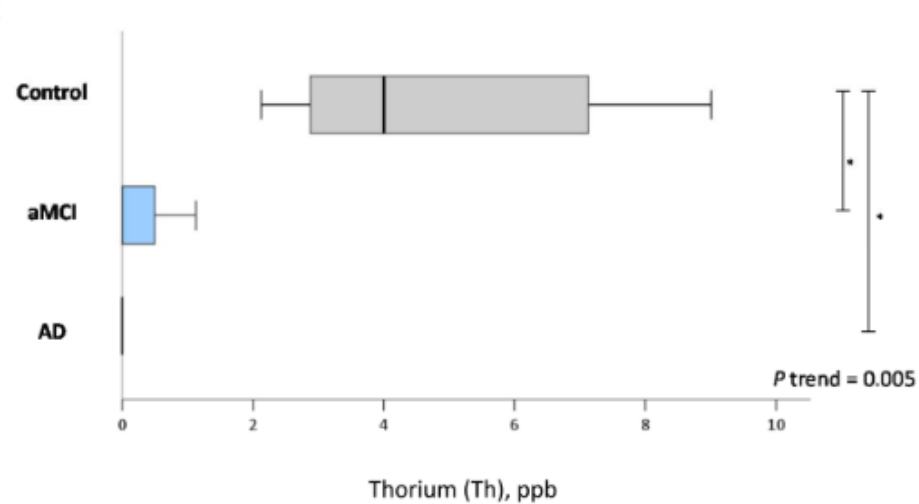

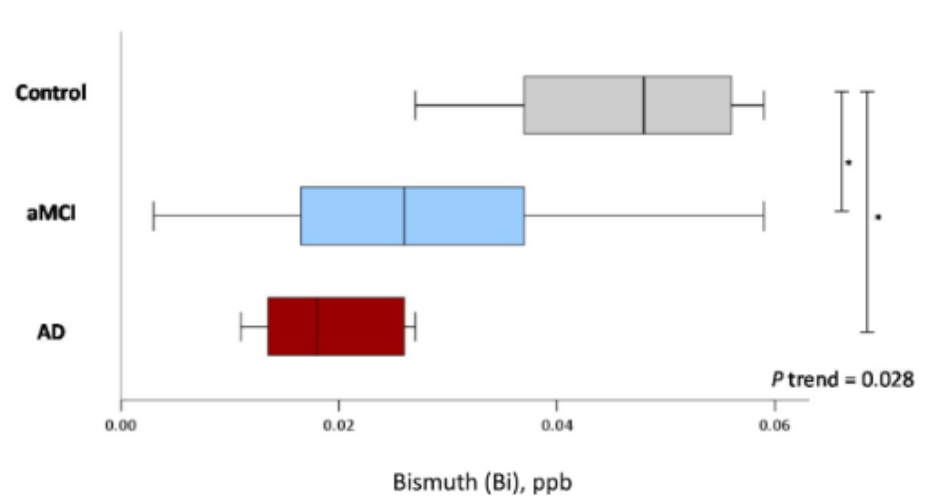

D

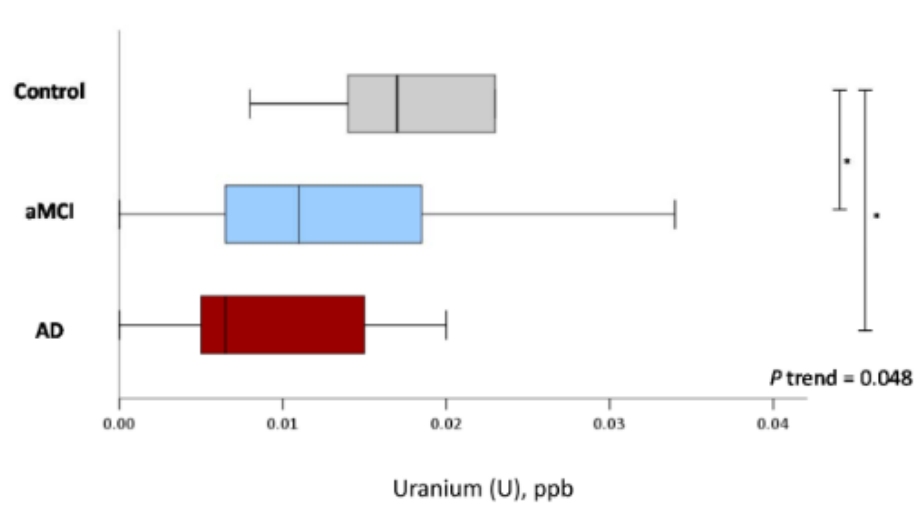

Figure 1

The distribution of trace metals according to disease groups. (A) Boron, (B) Bismuth, (C) Thorium, and (D) Uranium. aMCl, amnestic mild cognitive impairment; $A D$, Alzheimer's disease.

\section{Supplementary Files}

This is a list of supplementary files associated with this preprint. Click to download.

- renamed16882.docx 